\title{
Removal of Inhibitors of Bacterial Growth by Dialysis Culture
}

\author{
By PETER LANDWALL AND TORD HOLME \\ Department of Bacteriology, Karolinska Institutet, S-104 oI Stockholm, Sweden
}

(Received 3I May 1977)

\begin{abstract}
Dialysis culture was used to investigate the extent to which growth inhibition in bacterial cultures may be caused by accumulation of metabolites. Escherichia coli B was grown in a glucose/salts medium. A concentrated nutrient solution was pumped at a constant rate into the growing culture to ensure that growth was not limited by exhaustion of nutrients. In this way the only difference between growth conditions in dialysis and non-dialysis cultures was the transfer of dialysable metabolites from the culture vessel to the reservoir in the dialysis culture system. By adjusting the glucose concentration in the feed and maintaining a constant rate of feeding, glucose-limited growth could be achieved. Under these conditions, with oxygen in excess, bacterial yields of 140 to $150 \mathrm{~g}$ dry wt $1^{-1}$ were obtained in dialysis culture compared with 30 to $40 \mathrm{~g} \mathrm{l}^{-1}$ in non-dialysis culture. The high yields in dialysis culture depended on the removal of end-products of glucose metabolism. Growth inhibition was demonstrated to be the result of the combined influence of acetate, lactate, pyruvate, succinate, propionate and isobutyrate in concentrations found at the end of growth in non-dialysis cultures of Escherichia coli $\mathbf{\text { B. }}$
\end{abstract}

\section{INTRODUCTION}

A dialysis culture system consists of a culture chamber separated from a large nutrient reservoir by a dialysis membrane. Using a dialysis fermenter system with a separate dialyser, Gallup \& Gerhardt (1963) obtained extremely high yields of Serratia marcescens, and they ascribed this result to the continued provision of nutrients from the reservoir to the growing culture through the dialysis membrane.

Micro-organisms belonging to 40 different genera, including algae, bacteria, fungi and protozoa, have been grown in dialysis culture (see review by Schultz \& Gerhardt, 1969). In most of the studies reported, the equipment used was very simple, generally a dialysis sac immersed in a liquid nutrient medium. The primary aim has been to increase the microbial yields. In most studies, a substantial increase was obtained, which can be ascribed not only to diffusion of nutrients from the reservoir medium to the culture, but also to the increase in buffer capacity of the dialysis culture compared with the control.

Because of the lack of proper control of $\mathrm{pH}$, oxygen availability, concentration of energy source and nutrients, many of these experiments are difficult to evaluate with regard to microbial yield in relation to consumption of energy source and nutrient factors. With the dialyser-dialysis system devised by Gallup \& Gerhardt (1963), dialysis culture can be performed in a stirred fermenter with control of the above-mentioned parameters. Dialysis culture implies that two functions are imposed on a culture system: (i) energy sources and nutrients are supplied to the growing culture; (ii) dialysable end-products of metabolism are removed from the growing culture. The first function of the system may be replaced by feeding, i.e. supplying the culture with a concentrated nutrient solution, the volume increase of the culture being negligible. The second function, however, is a special feature of dialysis culture and can only rarely be replaced by other means. 
In the present paper, we report studies of the yields of Escherichia coli grown in glucose/ salts medium in dialysis culture. We achieved bacterial concentrations of the same magnitude as those reported for Serratia marcescens by Gallup \& Gerhardt (I963). Our studies were done in a dialysis fermenter system where nutrients were supplied to the culture at a constant rate, glucose being the growth rate-limiting nutrient. By feeding in this way, the cultures were kept well aerated in spite of the high cell densities and growth limitation by nutrient exhaustion was excluded. The difference in growth conditions between dialysis culture and a non-dialysis culture was thus confined to the removal of metabolites in the former system.

\section{METHODS}

Bacterial strain. Escherichia coli strain B was used in these studies.

Culture equipment. Bacteria were grown in aerated stirred fermenters with working volumes of 2.51 and I 1 (FL I03 and FL IOI, Biotec, Stockholm, Sweden). A Io 1 fermenter (Biotec FL I Io) was used as a nutrient reservoir for the dialysis experiments. A Biotec LP-100 instrument panel was used, including stirrer motor, automatic pH-titrator and temperature controls. A combined pH-electrode (type GK 2302 or GK 2303, Radiometer, Copenhagen, Denmark) was used. Dissolved oxygen was measured using a galvanic electrode (Borkowski \& Johnson, 1967). The instrument panel was connected to a Biotec LP 100-7 recorder. The dialyser (obtained from Ph. Gerhardt, Michigan State University, East Lansing, Michigan, U.S.A.) was a sterilizable, plate-and-frame type dialyser with up to eight chambers separated by silicone spacers (Schultz \& Gerhardt, 1969). Cellophane membranes permeable for molecules of molecular weight less than 10000 were used (Hi-sep, Graver Water Conditioning Co., New York, U.S.A.). The dialytic capacity had been determined by Gallup \& Gerhardt (1963). At full capacity the membrane area was approximately $0.23 \mathrm{~m}^{2}$. Modified hose pressure pumps (Manostat, New York, U.S.A.) were used for pumping the culture and the nutrient medium in the reservoir through the dialyser at a flow rate of $4.51 \mathrm{~min}^{-1}$. A peristaltic pump (LKB Varioperpex 12000) was used for feeding. The gas flow was measured by a Brookes type R-2-I 5-B gas flowmeter.

Culture conditions. The nutrient medium contained: glucose, $20 \mathrm{~g}$ (preculture $4 \mathrm{~g}$ ); $\mathrm{NH}_{4} \mathrm{Cl}, 8 \mathrm{~g}$ (preculture, ${ }_{2}^{\prime} \mathrm{g}$ ); $\mathrm{Na}_{2} \mathrm{HPO}_{4} .2 \mathrm{H}_{2} \mathrm{O}, 7.5 \mathrm{~g} ; \mathrm{KH}_{2} \mathrm{PO}_{4}, 3.0 \mathrm{~g} ; \mathrm{Na}_{2} \mathrm{SO}_{4} \cdot \mathrm{IOH}_{2} \mathrm{O}, 2.5 \mathrm{~g}$ (preculture $0.2 \mathrm{~g}$ ); $\mathrm{MgSO}_{4} .7 \mathrm{H}_{2} \mathrm{O}, 0.2 \mathrm{~g}$; and distilled water to $\mathrm{I}$ 1. A trace elements solution was also added (Holme et al., 1970). Polypropylene glycol P-2000 was added as an antifoam agent at $0.05 \mathrm{ml}(\mathrm{l} \text { medium })^{-1}$. During growth of the culture, the concentration of nutrients was kept at predetermined levels by feeding with a $60 \%(\mathrm{w} / \mathrm{v})$ glucose solution, supplemented with $\mathrm{NH}_{4} \mathrm{Cl}\left(\mathrm{I} 20 \mathrm{~g}^{-1}\right), \mathrm{Na}_{2} \mathrm{SO}_{4} \cdot \mathrm{IOH}_{2} \mathrm{O}\left(24 \mathrm{~g} \mathrm{l}^{-1}\right), \mathrm{MgSO}_{4} \cdot 7 \mathrm{H}_{2} \mathrm{O}\left(8 \mathrm{~g}^{-1}\right)$ and trace elements solution $\left(20 \mathrm{ml} \mathrm{l}^{-1}\right)$. In experiments carried out with trace elements at to times higher concentrations in the feeding liquid, no toxic effects of accumulated ions were noted. Unless otherwise stated, pure oxygen was added to the inflowing gas when the aeration efficiency was insufficient to keep the dissolved oxygen 'concentration in the culture above $20 \%$ of saturation.

Culture methods. Precultures, grown overnight in Erlenmeyer flasks on a rotary shaker, were centrifuged and resuspended in fresh medium before inoculation. For inoculation, bacteria were added to the fermenter to an initial concentration of $0.5 \mathrm{~g}$ dry wt $1^{-1}$. During the fermenter cultivations, $\mathrm{pH}$ was kept constant at 7.0 by automatic titration with $5 \mathrm{M}-\mathrm{NaOH}$, the temperature at $37^{\circ} \mathrm{C}$, the stirrer speed at $800 \mathrm{rev}$. $\mathrm{min}^{-1}$ and the gas flow rate at I $1 \mathrm{~min}^{-1}(1 \text { culture })^{-1}$. The oxygen transfer rate was approximately $120 \mathrm{mmol} \mathrm{l}^{-1} \mathrm{~h}^{-1}$ in both fermenters (Cooper, Fernstrom \& Miller, 1944).

During dialysis culture, the flow rates through the dialysis chambers were kept constant at $0.51 \mathrm{~min}^{-1} \mathrm{per}$ chamber. Flow rates above this value did not increase the efficiency of dialysis. Samples of $10 \mathrm{ml}(\mathrm{I} \mathrm{ml}$ at cell concentrations above $40 \mathrm{~g}$ dry wt $\mathrm{l}^{-1}$ ) were taken every hour for analysis. These were centrifuged and the supernatants were stored at $-20^{\circ} \mathrm{C}$. The bacteria were washed with $3 \mathrm{ml} \mathrm{o} \cdot \mathrm{OI} \mathrm{M}$-phosphate buffer $\mathrm{pH} 7 \cdot 0$ containing $1 \%(w / v)$ formaldehyde and dried in an oven at $110{ }^{\circ} \mathrm{C}$ for weight determination. The culture volume was kept constant during the whole culture period since the volumes of titrant and feed added to the culture vessel were equal to the sample volumes.

Analytical methods. The glucose concentration in the supernatants was determined by the glucose oxidase method (Glox, Kabi, Stockholm, Sweden). The salt concentrations were estimated by conductivity measurements (conductivity meter $\mathrm{CDM}_{3}$, Radiometer) to check that salts did not accumulate to inhibitory concentrations as a consequence of feeding and addition of sodium hydroxide. End-products formed by the culture were analysed by gas chromatography using a Varian Aerograph I400 with a flame ionization detector (Varian Aerograph, Walnut Creek, California, U.S.A.). Samples were prepared according to Bricknell \& Finegold (1973). For volatile end-products, a $6 \%$ FFAP on Porapak Q column was used. The methyl ester derivatives of non-volatile products were separated on a $10 \%$ Reoplex 400 on acid-washed Chromosorb W column (Harmon \& Doelle, 1969). 


\section{Table I. Aerobic growth of E. coli в in glucose/salts medium in stirred fermenters with and without feeding}

The culture volume was 2.51 . Maximal aeration efficiency in all experiments corresponded to I $20 \mathrm{mmol} \mathrm{O}_{2} \mathrm{l}^{-1} \mathrm{~h}^{-1}$ as determined by the sulphite oxidation method. In experiments I and 3, the dissolved oxygen (DO) was initially at $100 \%$ of saturation, but decreased with increasing oxygen demand during cultivation and became zero at a cell density of $6 \mathrm{~g} \mathrm{l}^{-1}$; further growth was thus oxygen-limited. In experiments 2 and 4, the dissolved oxygen was kept above $20 \%$ of saturation.

\begin{tabular}{|c|c|c|c|c|}
\hline \multirow[b]{3}{*}{ Experiment } & \multicolumn{2}{|c|}{ No feeding } & \multicolumn{2}{|c|}{$\begin{array}{c}\text { Feeding } \\
\text { (glucose-limited growth) }\end{array}$} \\
\hline & $\widehat{\mathrm{DO}} \rightarrow \mathrm{O}$ & DO $>20 \%$ & DO $\rightarrow 0$ & $\mathrm{DO}>20 \%$ \\
\hline & I & 2 & 3 & 4 \\
\hline Maximal cell dry weight $\left(\mathrm{g}^{-1}\right)$ & II $\cdot 8$ & $5 \cdot 5$ & 18 & 32 \\
\hline Glucose consumed $\left(\mathrm{g} \mathrm{l}^{-1}\right)$ & 40 & IO & 90 & 100 \\
\hline$Y_{\mathrm{G}}{ }^{*}$ & 54 & 99 & 36 & 58 \\
\hline
\end{tabular}

\section{RESULTS}

Experiments in non-dialysis culture

Cell yields obtained by growth in fermenters under different conditions of oxygen saturation with and without feeding are given in Table I. Experiment I illustrates the low substrate conversion efficiency obtained when the initial glucose concentration was $40 \mathrm{~g}^{-1}$. After a few hours growth, the oxygen demand of the culture exceeded the maximal aeration efficiency and the dissolved oxygen concentration fell to zero. The growth was then linear (Holme \& Brookes, 1969) and the growth rate was proportional to the oxygen transfer rate. Under these conditions of oxygen-limited growth, i.e. above a cell density of $6 \mathrm{~g} \mathrm{l}^{-1}$, the substrate conversion efficiency (expressed as $\mathrm{g}$ bacterial dry wt produced per mol glucose consumed, $Y_{G}$ ) was not optimal. In experiment 2 the initial glucose concentration was $10 \mathrm{~g} \mathrm{l}^{-1}$ and all glucose was consumed before the dissolved oxygen concentration reached zero. Thus, the molar growth yield $\left(Y_{G}\right)$ was 99 in this experiment, compared with 54 in experiment $\mathrm{I}$.

Glucose-limited growth could be obtained by feeding glucose to the growing culture. The rate of growth was then linear, and controlled by the rate at which glucose was supplied to the culture. The oxygen demand was therefore constant and oxygen limitation could be avoided by keeping the oxygen demand lower than the maximal aeration efficiency. By using this method (experiment 4, Table I), a very high cell yield was achieved. Oxygen was not limiting at any time during the cultivation, but in spite of this $Y_{\mathrm{G}}$ was only $5^{8}$, indicating that factors other than oxygen limitation might be responsible for the decrease in the effectiveness of the substrate conversion. In experiment 3 , the dissolved oxygen was kept at zero in a glucose-limited culture and the $Y_{\mathrm{G}}$ value was then lower than in experiment 4.

\section{Experiments in dialysis culture}

In the dialysis culture, much higher cell yields were obtained (Table 2). The culture conditions in the experiments represented in Table 2 were the same as in experiment 4 (Table 1 ), except for dialysis. The final cell yields were increased from 32 to $\mathrm{I}_{44} \mathrm{~g}^{-1}$ (Fig. I). The effectiveness of dialysis influenced the results. A dialysis culture volume ratio of $I: 4$ was not sufficient for optimal growth, i.e. the removal of inhibitory metabolites was too slow. The best bacterial yields were obtained under glucose-limiting conditions with oxygen in excess. In the dialysis culture experiment with a volume ratio of I : I I (Fig. I) glucose was fed at a rate corresponding to $9 \mathrm{~g}^{-1} \mathrm{~h}^{-1}$. Since glucose was supplied by diffusion from the reservoir, the glucose consumption during the period of growth under conditions of glucose limitation 
Table 2. Growth of $E$. coli $\mathrm{B}$ in glucose/salts medium in dialysis culture

The growth rate was regulated by feeding, glucose being the limiting factor. Oxygen was in excess, with dissolved oxygen at above $20 \%$ of saturation.

Maximal cell dry weight $\left(\mathrm{g}^{-1}\right)$

Glucose consumed $\left(\mathrm{g}^{-1}\right)$

$Y_{G}{ }^{*}$

Ratio of culture volume to

(culture+reservoir) volume

* Molar growth yield (g bacterial dry wt per mol glucose consumed).

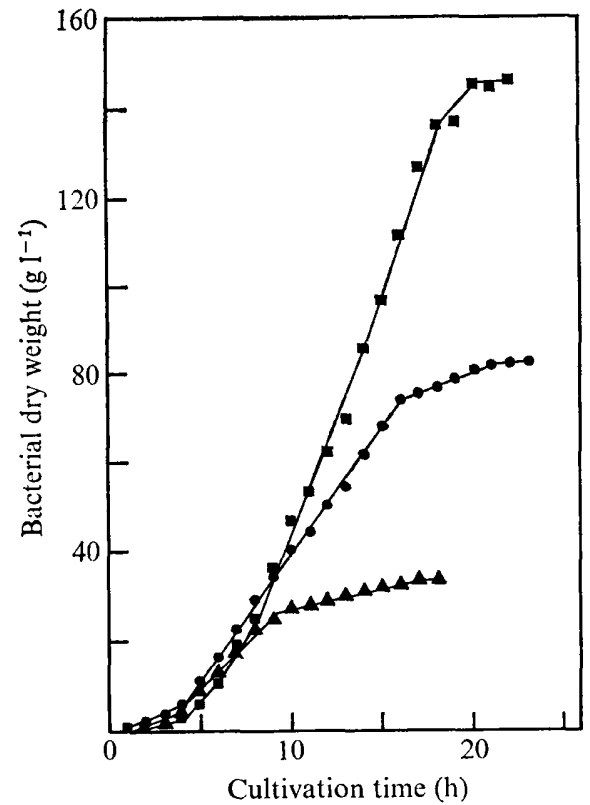

Fig. I

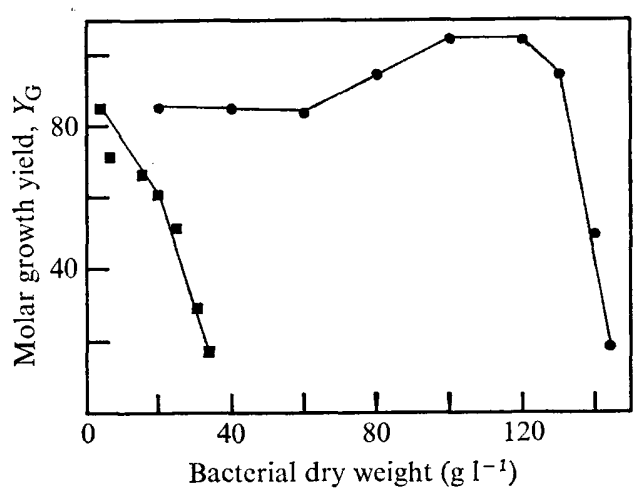

Fig. 2

Fig. 1. Growth of $E$. coli in glucose/salts medium with and without dialysis. Nutrients were fed into the cultures during growth. Growth rate was limited by the supply of glucose in the feed. Oxygen was in excess, with dissolved oxygen above $20 \%$ of saturation. $\square$, Dialysis culture volume ratio $\mathrm{I}: \mathrm{I} \mathrm{I} ; \boldsymbol{O}$, dialysis culture volume ratio $\mathrm{I}: 4 ; \boldsymbol{\Delta}$, non-dialysis culture.

Fig. 2. Growth yield with respect to glucose, $Y_{\mathrm{G}}$ (g bacterial dry wt per mol glucose consumed) at different cell densities in dialysis and non-dialysis cultures. Glucose-limited growth was maintained by feeding. Dissolved oxygen was kept above $20 \%$ of saturation. Dialysis culture; $\square$, non-dialysis culture.

decreased from 24 to $20 \mathrm{~g}^{-1} \mathrm{~h}^{-1}$ with the decrease in glucose concentration in the reservoir. As can be seen in Fig. $I$, the increase in bacterial mass was almost linear which means that $Y_{\mathrm{a}}$ was constant within the limits of experimental error. The mean value calculated for the period 8 to $18 \mathrm{~h}$ of cultivation was 93 . Since the rate of increase in cell mass was regulated by the glucose supply it was possible to regulate manually the admixture of oxygen to keep the level of dissolved oxygen in the culture above $20 \%$ of saturation.

A more detailed analysis of the growth inhibition which occurred at increasing cell densities was done by calculating $Y_{\mathrm{G}}$ for different intervals during the cultivations. In Fig 2, one non-dialysis and one dialysis culture are represented; both cultures were glucose-limited. 


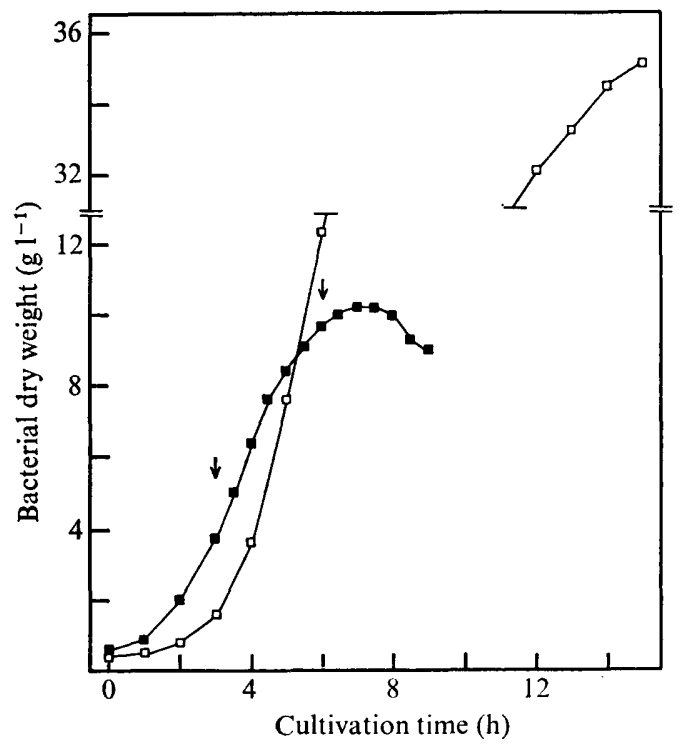

Fig. 3. Growth inhibition by organic acids in non-dialysis culture at $\mathrm{pH} 7 \cdot 0$. Addition of the mixture of acids (see Results) was started after $3 \mathrm{~h}$ cultivation (first arrow). The second arrow indicates the time at which the amounts of acids added corresponded to concentrations found at the end of a glucose-fed, non-dialysis culture. The glucose concentration was kept above $5 \mathrm{~g} \mathrm{l}^{-1}$ by feeding. Dissolved oxygen was kept above $20 \%$ of saturation. Growth curves: $\square$, control culture; $\mathbf{n}$, culture to which mixture of acids was added.

When dissolved oxygen was kept at values above $20 \%$ of saturation, the $Y_{\mathrm{a}}$ value was initially between 85 and IOO. During the cultivation, $Y_{G}$ decreased very rapidly in the nondialysis culture (Fig. 2). In the dialysis culture, this decrease occurred much later, indicating that the metabolites removed by dialysis exerted their inhibitory action by interfering with the energy metabolism of the bacteria. $Y_{a}$ was plotted against the cell concentration, since it was supposed that the growth inhibition depended on metabolites resulting from glucose degradation. These curves give a quantitative measure of the influence of the inhibitory metabolic products and of the ability of the dialysis system to remove them from the culture.

\section{Growth inhibition by metabolites}

To see whether end-products of fermentative degradation of glucose were responsible for the finding that growth was inhibited earlier in non-dialysis than in dialysis cultures, cultures were analysed for these metabolites by gas-liquid chromatography. At the end of growth in a fermenter culture grown in the glucose/salts medium at $\mathrm{pH} 7.0$ the following concentrations of organic acids were recorded $\left(\mathrm{g}^{-1}\right)$ : lactate, $\mathrm{I} \cdot 3$; pyruvate, $\mathrm{I} \cdot 3$; succinate, $\mathrm{I} \cdot 8$; propionate, 0.5 ; isobutyrate, 0.3 ; and acetate, I0. None of these acids added alone in the above concentrations to a culture growing at $\mathrm{pH} 7 \cdot 0$ caused growth inhibition; however, when a mixture of all the acids was added slowly to a growing culture, growth stopped soon after these concentrations were reached (Fig. 3). In this experiment, a culture growing with glucose and oxygen in excess was used. In the control culture, to which only glucose was fed, growth continued to a high density ( $35 \mathrm{~g} \mathrm{l}^{-1}$ at $\mathrm{I} 5 \mathrm{~h}$ ). Addition of acids to the other culture, was started after $3 \mathrm{~h}$, at a rate which was adjusted to give the above-mentioned concentrations in $3 \mathrm{~h}$, i.e. after $6 \mathrm{~h}$ cultivation (Fig. 3). A retardation of growth was observed $\mathrm{I} \cdot 5 \mathrm{~h}$ after the start of addition of acids, but growth continued at a decreasing rate for $3.5 \mathrm{~h}$. Samples of culture fluid were analysed by gas-liquid chromatography every hour during the addition of the organic acids. All acids were detected in concentrations which corresponded to the amounts added. 
The concentrations of organic acids in dialysis culture were very small even at high cell densities. In the culture with a volume ratio of I : I I (Fig. I), the acetate concentration was $0.2 \mathrm{~g}^{-1}$ in the culture fluid at a bacterial density of $100 \mathrm{~g} \mathrm{l}^{-1}$ and $0.07 \mathrm{~g}^{-1}$ in the reservoir. At the end of growth (bacterial density ${ }^{4} 44 \mathrm{~g} \mathrm{l}^{-1}$ ) the concentrations of the metabolites had increased to inhibitory concentrations (acetate $9 \mathrm{~g}^{-1}$, other acids in amounts similar to those mentioned above for non-dialysis culture).

\section{DISCUSSION}

The use of a nutrient feed combined with dialysis cultivation made it possible to obtain continued growth of Escherichia coli up to very high yields. This could be ascribed to the removal of auto-inhibitory metabolites formed during growth. The formation of autoinhibitory substances during growth of microbial cultures has been demonstrated in a number of studies. Growth of Shigella flexneri was completely inhibited by acetic acid at r.8 mM (Baskett \& Hentges, 1973). This inhibition was shown to depend on the undissociated acid, since adjustment of the $\mathrm{pH}$ from 6 to 7, which reduced the concentration of the undissociated acid ro-fold, completely reversed the inhibition. It was also shown that acetic acid interfered with the metabolism of glucose by the bacteria and not with its uptake. Weiner \& Draskoczy (196I) demonstrated a pH-dependent inhibitory effect of acetic acid on Escherichia coli.

Sheu \& Freese (1972) demonstrated growth inhibition of Bacillus subtilis by fatty acids. The inhibition correlated with a reduction in the rate of oxygen consumption and the concentration of ATP per cell. They put forward the hypothesis that the fatty acids reacted reversibly with the cytoplasmic membrane or proteins in it, thereby interfering with electron transport. In a subsequent paper, Sheu, Konings \& Freese (1972) showed that acetate and other short-chain fatty acids inhibited the concentrative uptake of amino acids, which is energized by the cytochrome-linked electron transport system.

Borichewski (1967) and Borichewski \& Umbreit (1966) showed that the strictly autotrophic bacterium Thiobacillus thiooxidans could grow on glucose as the sole energy source if the culture was continuously dialysed against fresh medium. Growth inhibition in the presence of glucose was caused by accumulation of pyruvic acid in the culture fluid. Pan \& Umbreit (1972) demonstrated that growth inhibition by keto acids occurred in cultures of five other autotrophic bacteria, including Nitrobacter species.

In addition to the experiments of Borichewski \& Umbreit (I966), dialysis culture has been used to produce concentrated cultures of Brucella abortus (Hauschild \& Pivnick, 196I), Bordetella pertussis (Black, I966), Mycoplasma sp. (Masover \& Hayflick, I974) and a number of other micro-organisms (Gerhardt \& Gallup, 1963). Quantitative studies, including calculation of yields on energy sources, were initiated by Gallup \& Gerhardt (1963), who used aerated fermenters and a separate dialyser, a system which permitted proper control of oxygen availability, $\mathrm{pH}$ and nutrient concentrations. Abbot \& Gerhardt (1970 $a, b, c)$ studied salicylic acid production and threonine biosynthesis and Friedman \& Gaden (I970) demonstrated increased yields of lactic acid by Lactobacillus delbrueckii in dialysis culture.

In a recent study of growth yields of an obligate methane-oxidizing bacterium, Naguib (1975) found repression of growth by accumulation of extracellular metabolic products. Methane-oxidizers are known to produce methanol and formaldehyde as intermediates in the oxidation of methane (Harwood \& Pirt, 1972). However, Naguib showed that a further, as yet unidentified, inhibitor accumulated in the cultures and obtained a substantial increase in cell densities by including a dialysis unit in the culture system.

Dialysis culture offers the most general solution to the problem of removing autoinhibitory metabolites. In special cases it may, however, be achieved by recirculation of the bacteria or by adding an adsorbent to the culture (Harwood \& Pirt, 1972). Recirculation of cells may be used when secondary metabolites are produced. The cell mass from a continuous 
culture is collected, generally by centrifugation, and a fraction of the cells is fed back into the culture. However, it has been shown that methane-oxidizing bacteria are damaged during centrifugation and that growth-inhibitory substances are released when the cells are added to the growing culture (D. E. Harrison, personal communication).

Feeding offers special advantages in combination with dialysis culture. Even if all nutrients needed for the growth of the bacteria could be present in the total medium volume (culture vessel plus reservoir), the membrane area would have to be very large to permit diffusion of nutrients at a speed sufficient for rapid growth of the culture. The application of feeding to a culture involves the calculation of the approximate requirements for essential medium components. The feed must balance the consumption of these components, ideally keeping their concentrations constant during the whole growth period. Very small amounts of the nutrients will then be present in the reservoir at the end of the cultivation relative to the high microbial yields obtained. It is also possible to regulate the growth rate by making one nutrient growth rate-limiting in the feed. If the energy source is made the limiting factor, this greatly simplifies the cultivation of aerobic bacteria, since the oxygen consumption per unit time will be proportional to the supply of the energy source during the period of limited growth.

The usefulness of dialysis culture for the production of bacterial cells does not only depend on the possibility of obtaining very high bacterial concentrations. An important feature is the more effective conversion of energy and carbon sources into cell material. Gallup \& Gerhardt (1963) reported $Y_{a}$ values of 36 in their dialysis culture studies, but this value was not significantly different from that of a non-dialysis culture. In contrast, our present studies have shown that when feeding of glucose and nutrients was used, the molar growth yield remained?at values between 85 and 100 during the extended growth obtained in dialysis culture (Fig. 2). In the non-dialysis culture, grown under the same conditions, $Y_{G}$ decreased rapidly from an initial value of 85 .

The growth-inhibitory effect of the accumulating metabolites appears to depend on their influence on $Y_{G}$. The effect of dialysis during cultivation is to remove these metabolites. This explanation of the growth-promoting effect of dialysis culture has been found to be true in several cases (Gerhardt \& Gallup, 1963; Abbott \& Gerhardt, 1970a, b).

This work was supported by grants from the Swedish Board for Technical Development (73-3744, 74-3469) and from Emil and Wera Cornells Stiftelse. The skilful technical assistance provided by Tove Harde is gratefully acknowledged.

\section{REFERENCES}

Abbott, B. J. \& Gerhardt, Ph. (1970a). Dialysis fermentation. I. Enhanced production of salicylic acid from naphthalene by Pseudomonas fluorescens. Biotechnology and Bioengineering 12, 577589.

Abbott, B. J. \& Gerhardt, Ph. (1970 $b$ ). Dialysis fermentation. II. Kinetic analysis of salicylic acid production via cell growth and maintenance. Biotechnology and Bioengineering 12, 59I-60I.

AвbotT, B. J. \& Gerhardt, Ph. (I970 c). Dialysis fermentation. III. Anomalous inhibition of threonine biosynthesis in an auxotrophic mutant of Escherichia coli. Biotechnology and Bioengineering 12, 603-613.

Basketr, R. C. \& Hentges, D. J. (1973). Shigella flexneri inhibition by acetic acid. Infection and Immunity 8, 91-97.

BLACK, S. H. (1966). Enhanced growth of Bordetella pertussis in dialysis culture. Nature, London 209, 105-106.
BoRICHEwSKI, R. M. (1967). Keto acids as growthlimiting factors in autotrophic growth of Thiobacillus thiooxidans. Journal of Bacteriology 93, 597-599.

BoricheWSKi, R. M. \& UMBREIT, W. W. (I966). Growth of Thiobacillus thiooxidans on glucose. Archives of Biochemistry and Biophysics 116, 97102.

Borkowski, J. D. \& Johnson, M. J. (1967). Longlived steam-sterilizable membrane probes for dissolved oxygen measurements. Biotechnology and Bioengineering 9, 635-639.

Bricknell, K. S. \& Finegold, S. M. (1973). A simple, rapid method to process and assay fatty acids and alcohols by gas chromatography. Analytical Biochemistry 5I, 23-3I.

Cooper, C. M., Fernstrom, G. A. \& Miller, S. A. (1944). Performance of agitated gas liquid contactors. Industrial and Engineering Chemistry 36, 504 . 
Friedman, M. R. \& Gaden, E. L., JR. (1970). Growth and acid production by Lactobacillus delbrueckii in a dialysis culture system. Biotechnology and Bioengineering 12, 961-974.

Gallup, D. M. \& Gerhardt, PH. (1963). Dialysis fermentor systems for concentrated culture of microorganisms. Applied Microbiology II, 506512.

Gerhardt, Ph. \& Gallup, D. M. (1963). Dialysis flask for concentrated culture of microorganisms. Journal of Bacteriology 86, 919-929.

HaRmoN, M. A. \& Doelle, H. W. (1969). Gas chromatographic separation and determination of microquantities of the esters of the tricarboxylic acid cycle acids and related compounds. Journal of Chromatography 42, 157-169.

HARWOOD, J. H. \& PIRT, S. J. (I972). Quantitative aspects of growth of the methane oxidizing bacterium Methylococcus capsulatus on methane in shake flask and continuous chemostat culture. Journal of Applied Bacteriology 35, 597-607.

Hauschild, A. H. \& Pivnick, J. (I961). Continuous culture of Brucella abortus si9. Canadian Journal of Microbiology 7, 491-499.

Holme, T. \& BROOKES, R. (1969). The influence of different energy sources on bacterial growth and synthesis. In Fermentation Advances, pp, 145-1 56. Edited by D. Perlman. New York: Academic Press.

Holme, T., Arvidson, S., Lindholm, B. \& Pavlu, B. (1970). Enzymes - laboratory scale production. Process Biochemistry 5 (9), 62-66.
Masover, G. K. \& Hayflick, L. (I974). Dialysis culture of T-strain mycoplasmas. Journal of Bacteriology 118, 46-52.

NAGUIB, M. (1975). Overall metabolic regulations in cultures of the obligate methane-oxidizing strain M102. In Microbial Growth on $C_{1}$-Compounds, Proceeding's of the International Symposium on Microbial Growth on $C_{1}$-Compounds, pp. 203-212. Tokyo, Japan: Society of Fermentation Technology.

PaN, P. \& UMBreIT, W. W. (1972). Growth of obligate autotrophic bacteria on glucose in a continuous flow-through apparatus. Journal of Bacteriology I09, I I 49-I I 55 .

Schultz, J. S. \& Gerhardt, Ph. (I969). Dialysis culture of microorganisms: design, theory and results. Bacteriological Reviews 33, I-47.

Sheu, C. W. \& Freese, E. (1972). Effects of fatty acids on growth and envelope proteins of Bacillus subtilis. Journal of Bacteriology III, 516-524.

Sheu, C. W., KonIngs, W. N. \& Freese, E. (1972). Effects of acetate and other short-chain fatty acids on sugar and amino acid uptake of Bacillus subtilis. Journal of Bacteriology III, 525-530.

WeInER, N. \& Draskoczy, P. (I96I). The effects of organic acids on the oxidative metabolism of intact and disrupted E. coli. Journal of Pharmacology and Experimental Therapeutics 132, 299305 . 